\title{
EVALUACION DEL EFECTO DEL ACIDO NALIDIXICO, AMPICILINA, KANAMICINA, PENICILINA G Y POLIMIXINA B EN LOS CULTIVOS DE PROMASTIGOTES DE LEISHMANIA
}

\author{
Sofia Duque Beltrán*, Augusto Corredor Arjona**, Marleny Montilla Moreno**, \\ Dioselina Peláez Carvajal****.
}

\begin{abstract}
Se evaluó el efecto de diferentes concentraciones de ácido nalidíxico, ampicilina, kanamicina, penicilina $\mathrm{G}$ y polimixina $\mathrm{B}$, sobre la población de promastigotes de Leishmania braziliensis braziliensis, Leishmania donovani chagasi y Leishmania mexicana amazonensis in vitro. La penicilina $G$ y la ampicilina se pueden utilizar hasta concentraciones de $1000 \mathrm{ug} / \mathrm{ml}$ y $500 \mathrm{ug} / \mathrm{ml}$ respectivamente en cultivo de promastigotes de cualquiercepa de Leishmania sin queéstosse afecten. LapolimixinaBdisminuyela población de promastigotes por lo cual es preferible no usarse en cultivos de Leishmania. El ácido nalidíxico y kanamicina pueden ser utilizados in vitro pero teniéndose en cuenta la especie de Leishmania y la concentración de antimicrobiano recomendado para la misma.
\end{abstract}

\section{INTRODUCCION}

Es importante el aislamiento y mantenimiento de cepas de Leishmania en cultivo porque ellas son el antígeno que se emplea tanto para las pruebas inmunodiagnósticas como para estudios bioquímicos e inmunológicos.

Los promastigotes que se mantienen en cultivo provienen de los amastigotes que han sido obtenidos a partir de biopsias ya sea de humanos o animales vertebrados. La fuente de origen de los parásitos puede contener microorganismos los cuales contaminan los cultivos impidiendo el mantenimiento de los promastigotes in vitro. La prioridad de conservar una cepa de Leishmania axénica ha llevado a los investigadores a buscar soluciones para eliminar los microorganismos. Un procedimien- to para tal fin es utilizar antibióticos que inhiban y eliminen los agentes contaminantes.

La adición de antibióticos en medios de cultivo ha sido discutida durante años $(1,2)$. Se pensaba que la adición de éstos sólo debería hacerse cuando se aislaran cepas de Leishmania. Sin embargo, con el tiempo se comprobó que una contaminación con hongos o bacterias era difícil de manejar in vitro y que aquellas se podían controlar y hasta eventualmente eliminar con antibióticos como gentamicina, penicilina y estreptomicina individualmente o en combinaciones.

Desde hace varios años se conoce que anfotericina B y pentamidina son activos contra la forma promastigote de Leishmania $(3,4)$ y que ciertos bactericidas como sulfadiazina,

\footnotetext{
* Bióloga, Grupo de Parasitología, Instituto Nacional de Salud

** Médico Cirujano, Jefe Grupo de Parasitología-Instituto Nacional de Salud, Profesor Facultad de Medicina-Universidad Nacional de Colombia

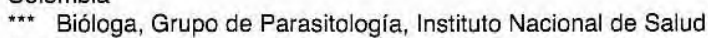

$* \star \star \star$ Bacterióloga, Grupo de Parasitología, Instituto Nacional de Salud
} 
sulfadoxina, sulfadimetoxina, trimetropin, isoniazida, rifampicina, isoniazida + rifampicina, tiambutosina, salicil-aldehidoisonicotin-hidrazona, acetil-sulfona, sulfitrona, ácido 4-amino salicílico y clofazimina tienen actividad antileishmania reduciendo la cantidad de macrófagos infectados (5).

El presente trabajo evalúa el efecto del ácido nalidíxico, ampicilina, kanamicina, penicilina $G$ y polimixina $B$ sobre el número de promastigotes de Leishmania pertenecientes al complejo braziliensis, mexicana y chagasi. Estos antimicrobianos son de fácil adquisición para los laboratorios donde se lleve a cabo cultivos de Leishmania y además poseen actividad de amplio espectro contra bacterias Gramnegativas y Gram-positivas.

\section{MATERIALES Y METODOS}

PARASITOS. Promastigotes de Leishmania braziliensis braziliensis (L.b.b.), Leishmania donovani chagasi (L.d.ch.) y Leishmania mexicana amazonensis (L.m.a.) mantenidos in vitro.

MEDIOS DE CULTIVO. La composición de los medios de cultivo NNN modificado (fase sólida) y RE I modificado (fase líquida) con sus respectivos procedimientos de elaboración fueron los descritos por Duque y Colaboradores (6).

CONDICIONES DE CULTIVO DE LAS CEPAS DE Leishmania. Los promastigotes de cada una de las cepas de Leishmania, fueron cultivados tanto sin antimicrobianos como con la adición de cada una de las concentraciones de éstos a estudiar. Los cultivos fueron sembrados por duplicado e incubados a $24^{\circ} \mathrm{C}$.

ANTIMICrobianos. Acido nalidíxico. Control $0 \mathrm{ug} / \mathrm{ml}$. Concentraciones de 30, 50 y $100 \mathrm{ug} /$ $\mathrm{ml}$

Ampicilina. Control $0 \mathrm{ug} / \mathrm{ml}$. Concentraciones de 100,300 y $500 \mathrm{ug} / \mathrm{ml}$

Kanamicina. Control $0 \mathrm{ug} / \mathrm{ml}$. Concentraciones de 50,100 y $200 \mathrm{ug} / \mathrm{ml}$

Penicilina G. Control $0 \mathrm{ug} / \mathrm{ml}$ Concentraciones de $500,1000 \mathrm{ug} / \mathrm{ml}$
Polimixina B. Control 0 U.I./ml. Concentraciones de 300,500 U.I./ml

\section{DETERMINACION DEL CRECIMIENTO POBLACIONAL}

El crecimiento de los flagelados en los medios de cultivo y en presencia de cada una de las concentraciones de los antimicrobianos anteriormente mencionados fue llevado a cabo mediante cuantificaciones periódicas de las poblaciones por $\mathrm{ml}$ utilizando la cámara de Neubauery partiendo para cada cepa de inóculos de poblaciones por $\mathrm{ml}$ conocidos.

\section{ANALISIS ESTADISTICO}

E1 incremento o disminución de promastigotes fue analizado mediante el test $t$ $(\mathrm{p}<0.05)$

\section{RESULTADOS}

\section{ACIDO NALIDIXICO}

Las poblaciones de promastigotes de $L$. braziliensis braziliensis, $L$. donovani chagasi y L. mexicana amazonensis en presencia de concentraciones de 30,50 y $100 \mathrm{ug} / \mathrm{ml}$ de ácido nalidíxico (Fig.1, 2 y 3) presentaron un incremento en el número de parásitos siendo éste más notorio durante los primeros cuatro días siguientes a su siembra inicial. Sin embargo, el incremento poblacional en cada especie comparado con su respectivo control fue menor en las distintas concentraciones del antimicrobiano.

El número de promastigotes obtenido frente a cada una de las concentraciones del ácido nalidíxico en $L . b$. braziliensis fue notoriamente menor y la fase logarítmica de crecimiento reducida.

Las diferencias en el incremento poblacional observadas en $L$. d. Chagasi y $L$. m. amazonensis en cada una de las concentraciones del ácido nalidíxico no fueron considerables con excepción del descenso observado en la concentración de $100 \mathrm{ug} / \mathrm{ml} \mathrm{al} 7^{\circ}$ día en L. m. amazonensis donde el número de parásitos disminuyó drásticamente. 
LEISHMANIA BRAZILIENSIS BRAZILIENSIS ACIDO NALIDIXICO
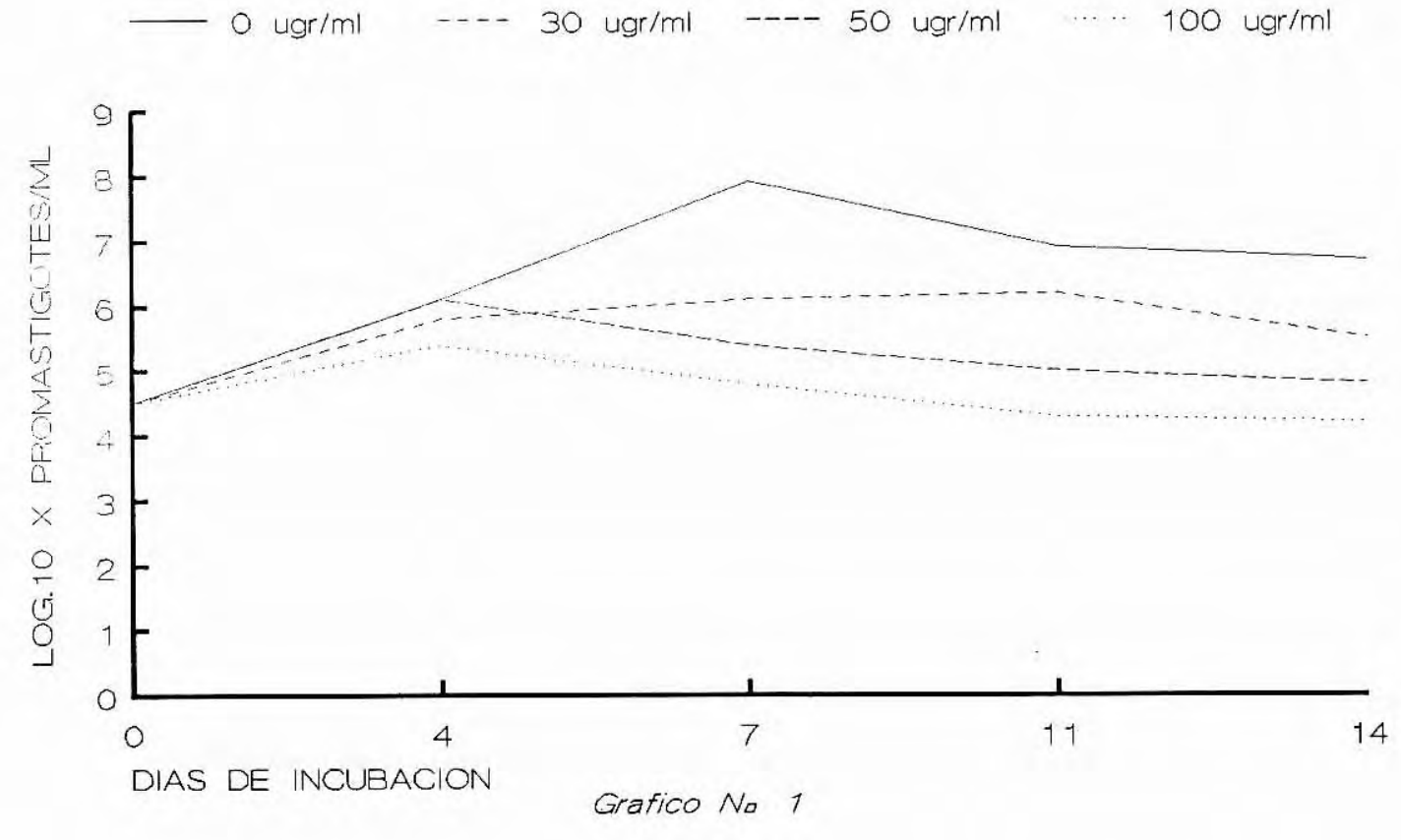

LEISHMANIA DONOVANI CHAGASI ACIDO NALIDIXICO

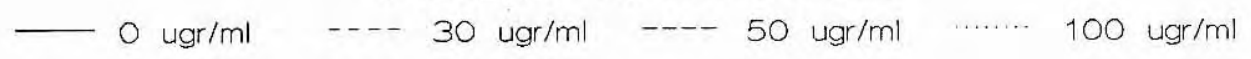

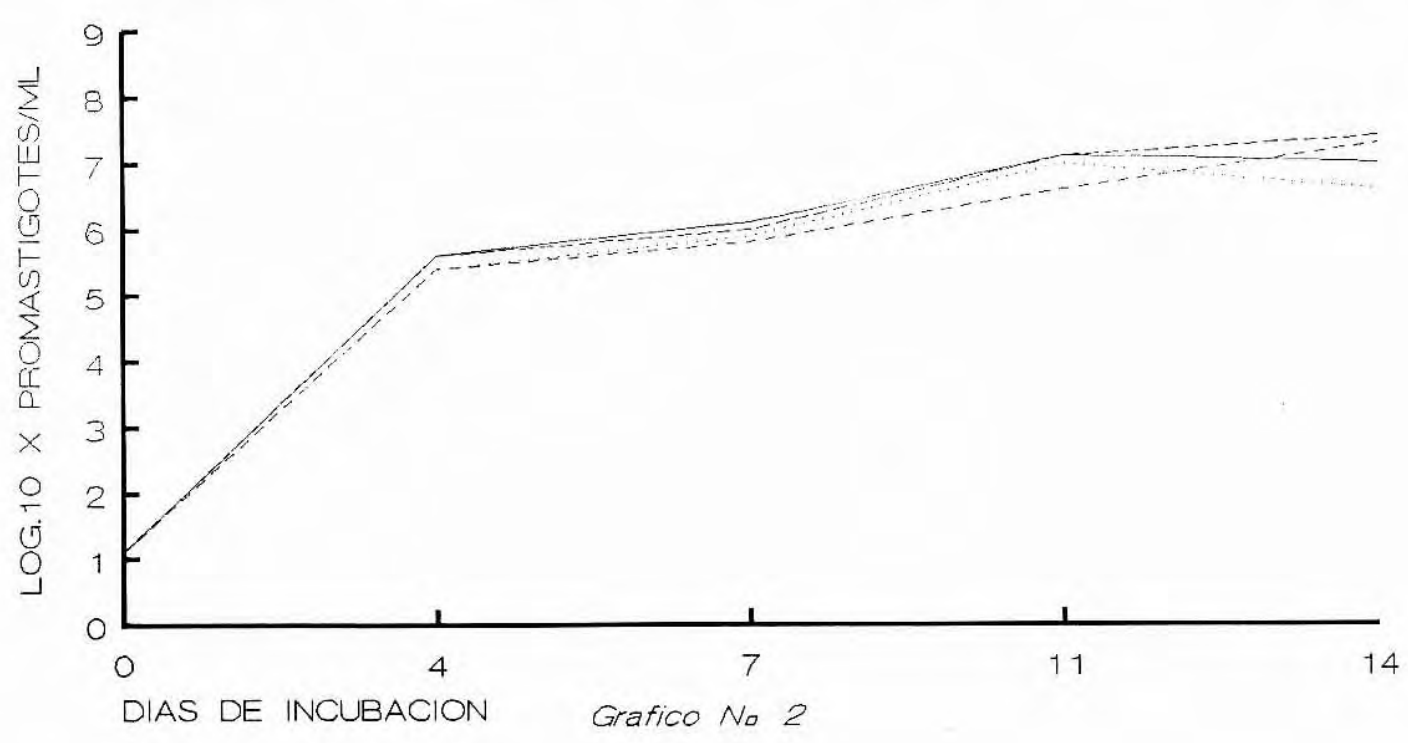



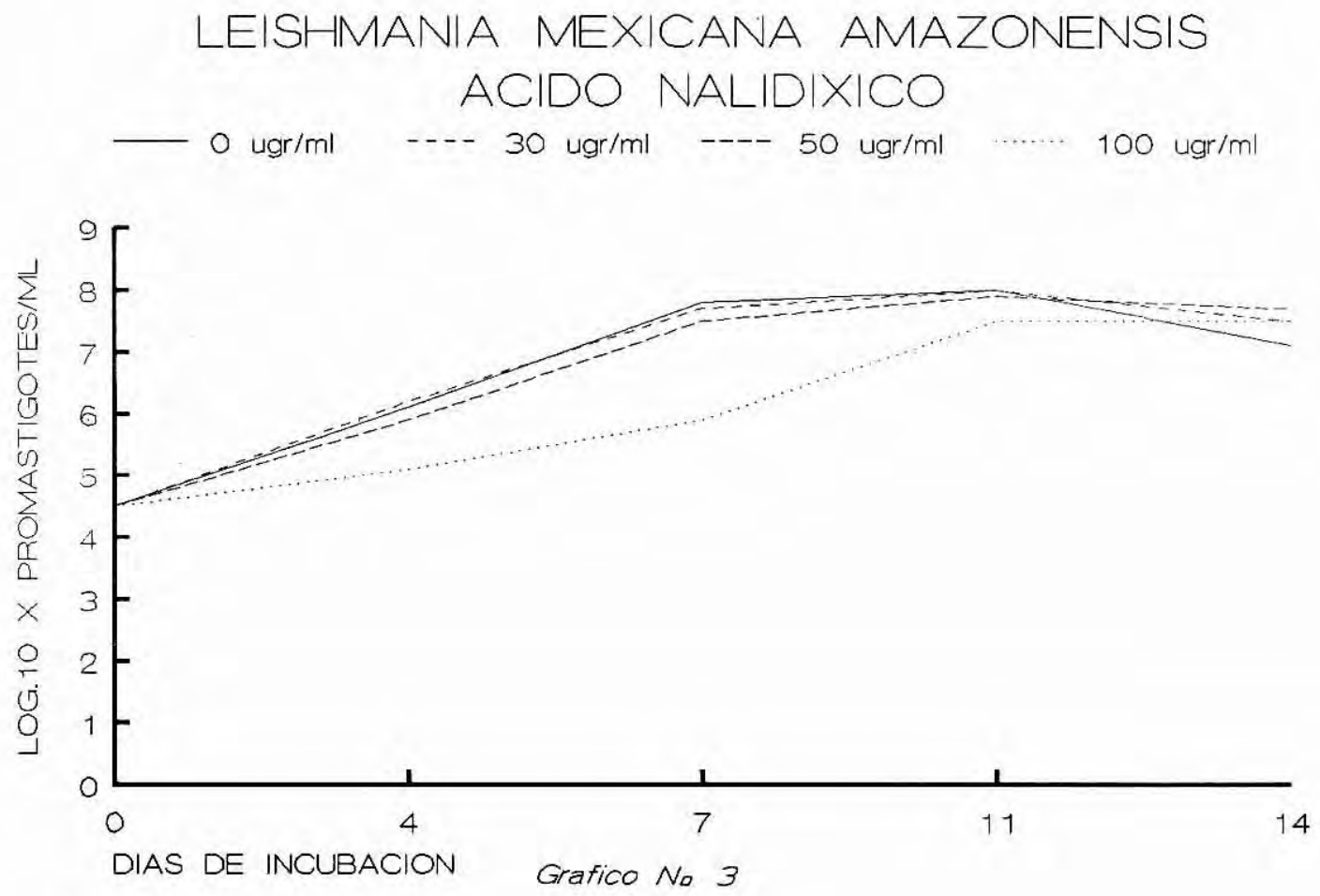

\section{AMPICILINA}

El incremento de parásitos de $L . b$. braziliensis, L. d. chagasi y L. m. amazonensis obtenido en cultivo no se afectó por la presencia de ampicilina en ninguna de las concentraciones empleadas (Fig.4, 5 y 6 ).

\section{KANAMICINA}

El aumento de promastigotes de L. b. braziliensis, L. d. chagasi y L. m. amazonensis en presencia de kanamicina en concentraciones de 50,100 y $200 \mathrm{ug} / \mathrm{ml}$ se afectó en forma diferente en cada una de las cepas (Fig.7, 8y 9). La población de parásitos de $L$. b. braziliensis (Fig.7) y $L$. m.amazonensis (Fig.9) en presencia dekanamicina en concentraciones de $50-200 \mathrm{ug} / \mathrm{ml}$ disminuyó a partir del día tercero. El incremento de promastigotes de $L$. d. chagasi (Fig.8) en presencia de kanamicina en las concentraciones ante- riormentemencionadas presentóundescensoleve, pero éste fue notorio al decímo día.

\section{PENICILINA G}

El crecimiento de promastigotes de $L$. $b$. braziliensis, $L$. d. chagasi y L. m. amazonensis in vitro no se afectó utilizando penicilina $\mathrm{G}$ en concentraciones de 500 y $1000 \mathrm{ug} / \mathrm{ml}$ durante los 14 días de cultivo de los parásitos (Fig.10, 11 y 12 ).

\section{POLIMIXINA B}

Este antibiótico produjo una disminución de parásitos en todas las cepas de Leishmania estudiadas. La reducción del número de promastigotes en la cepa de $L$. b.braziliensis fue leve y más notoria en las cepas de $L$. $d$. chagasi y L. m. amazonensis (Fig.13, 14 Y 15). 


\section{LEISHMANIA BRAZILIENSIS BRAZILIENSIS} AMPICILINA

O ugr $/ \mathrm{ml} \quad--$ - $100 \mathrm{ugr} / \mathrm{ml}$---- $300 \mathrm{ugr} / \mathrm{ml} \cdots \ldots . .500 \mathrm{ugr} / \mathrm{ml}$

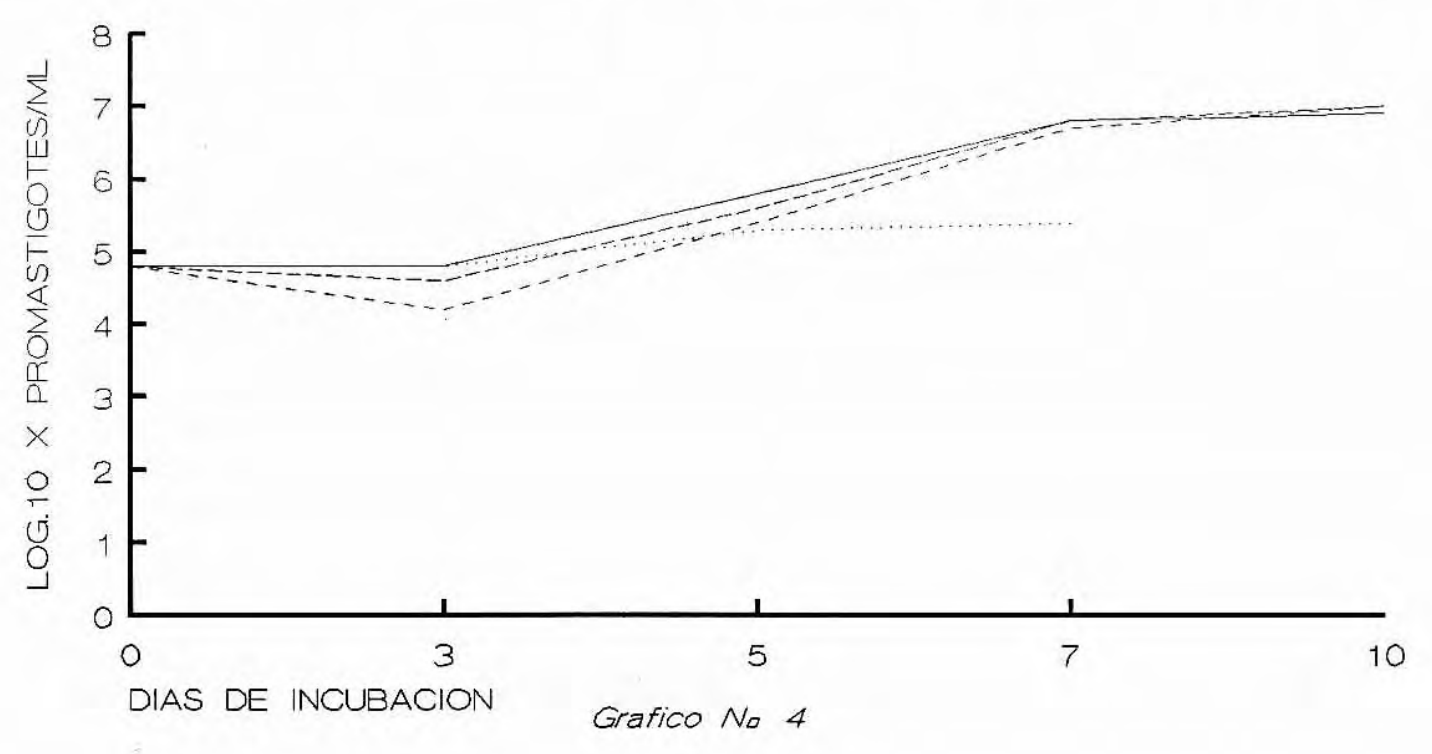

\section{LEISHMANIA DONOVANI CHAGASI} AMPICILINA

- $0 \mathrm{ugr} / \mathrm{ml} \ldots 100 \mathrm{ugr} / \mathrm{ml}$-.-- $300 \mathrm{ugr} / \mathrm{ml} \ldots \ldots . .500 \mathrm{ugr} / \mathrm{ml}$

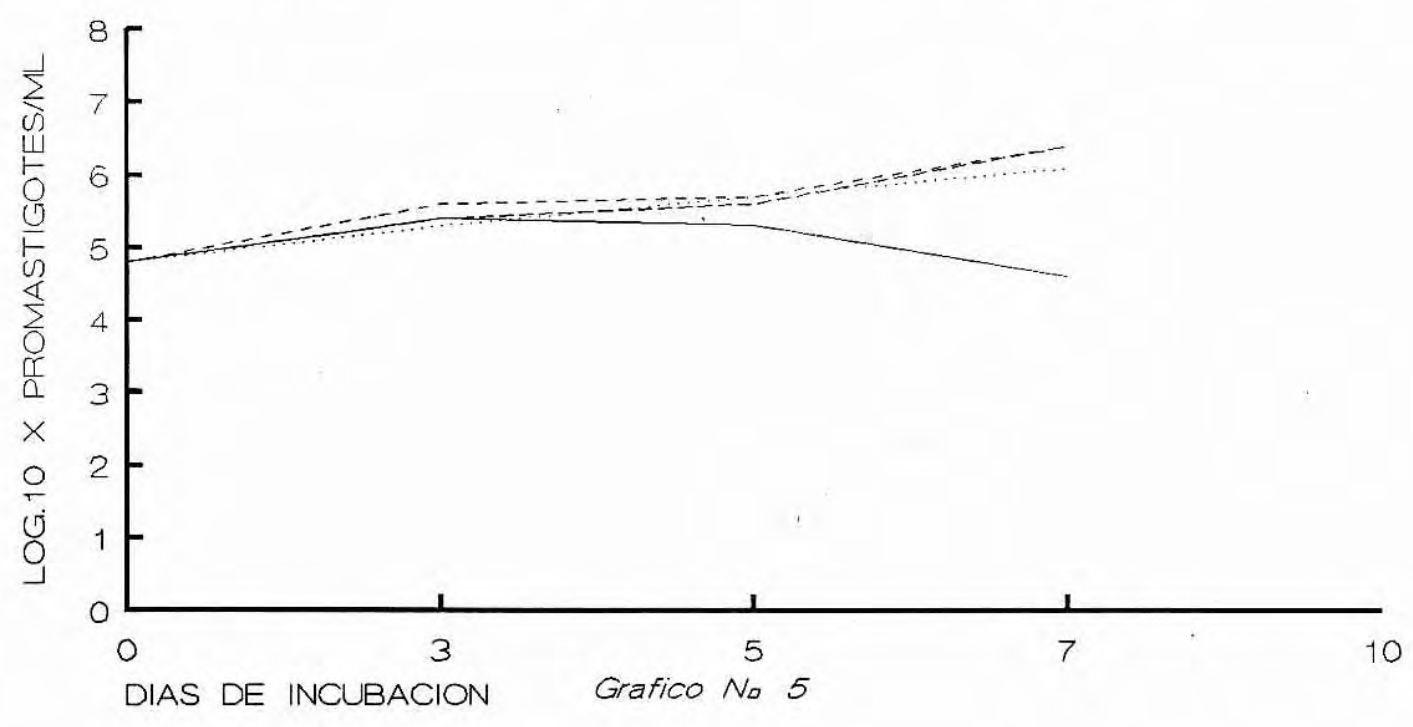


EVALUACION DEL EFECTO DEL ACIDO NALIDIXICO, AMPICILINA, KANAMICINA, PENICILINA G Y POLIXINA B,....

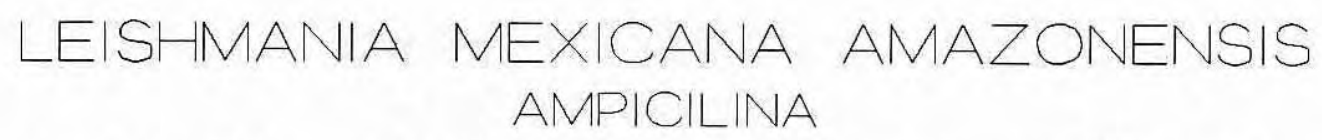

- $0 \mathrm{ugr} / \mathrm{ml} \ldots . .100 \mathrm{ugr} / \mathrm{ml} \ldots--300 \mathrm{ugr} / \mathrm{ml} \ldots . . . .5500 \mathrm{ugr} / \mathrm{ml}$
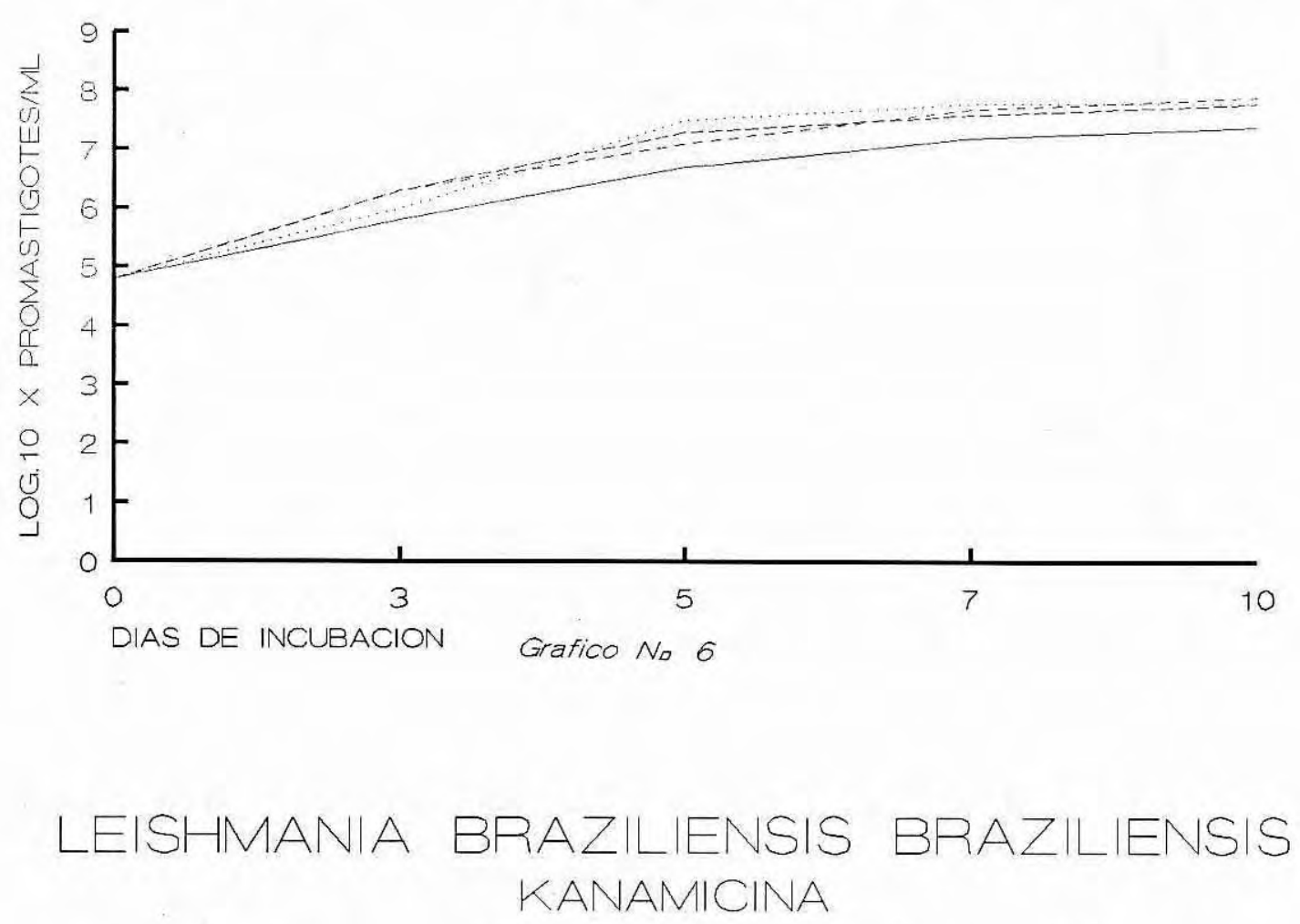

- $0 \mathrm{ugr} / \mathrm{ml} \ldots-.50 \mathrm{ugr} / \mathrm{ml} \ldots-\ldots 100 \mathrm{ugr} / \mathrm{ml} \mathrm{\ldots .......} 200 \mathrm{ugr} / \mathrm{ml}$

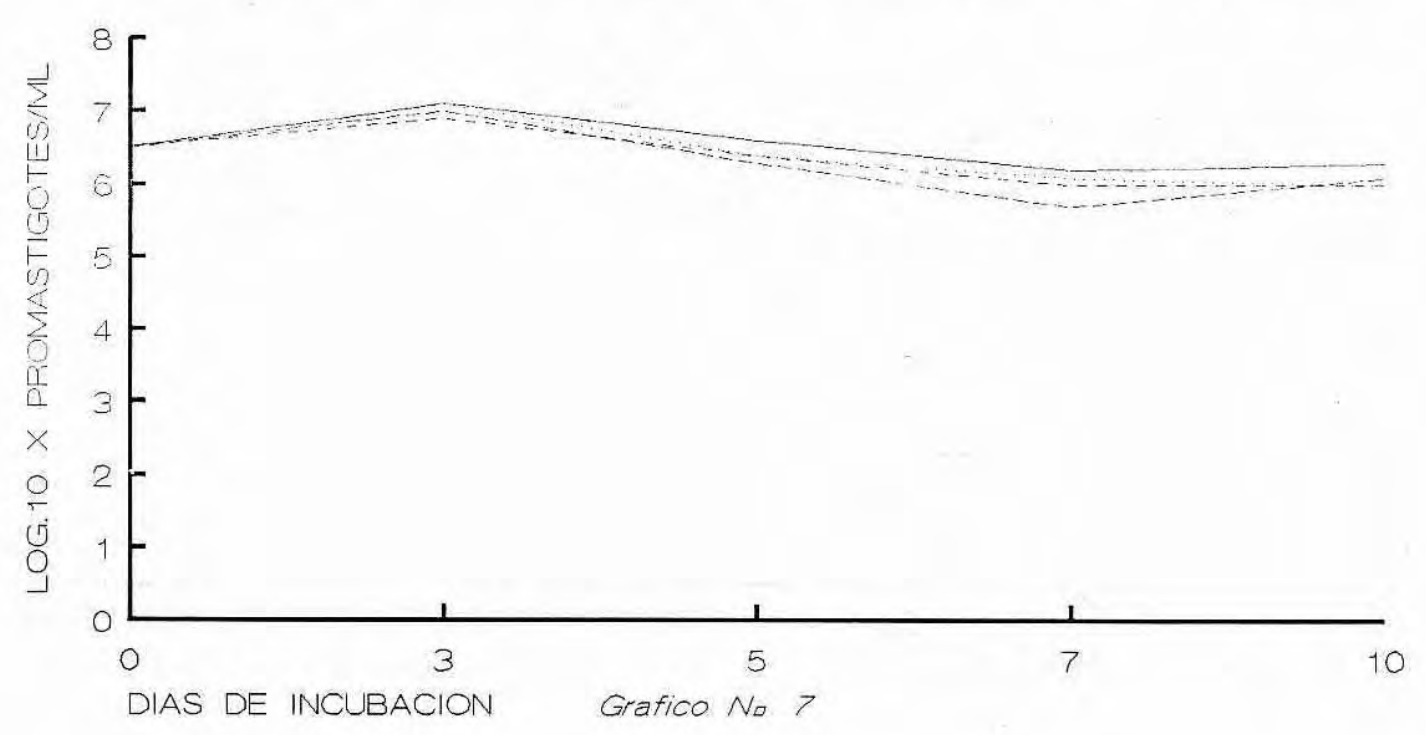




\section{LEISHMANIA DONOVANI CHAGASI KANAMICINA}

- $0 \mathrm{ugr} / \mathrm{ml} \ldots 50 \mathrm{ugr} / \mathrm{ml} \ldots-.-100 \mathrm{ugr} / \mathrm{ml} \cdots \cdots . .200 \mathrm{ugr} / \mathrm{ml}$

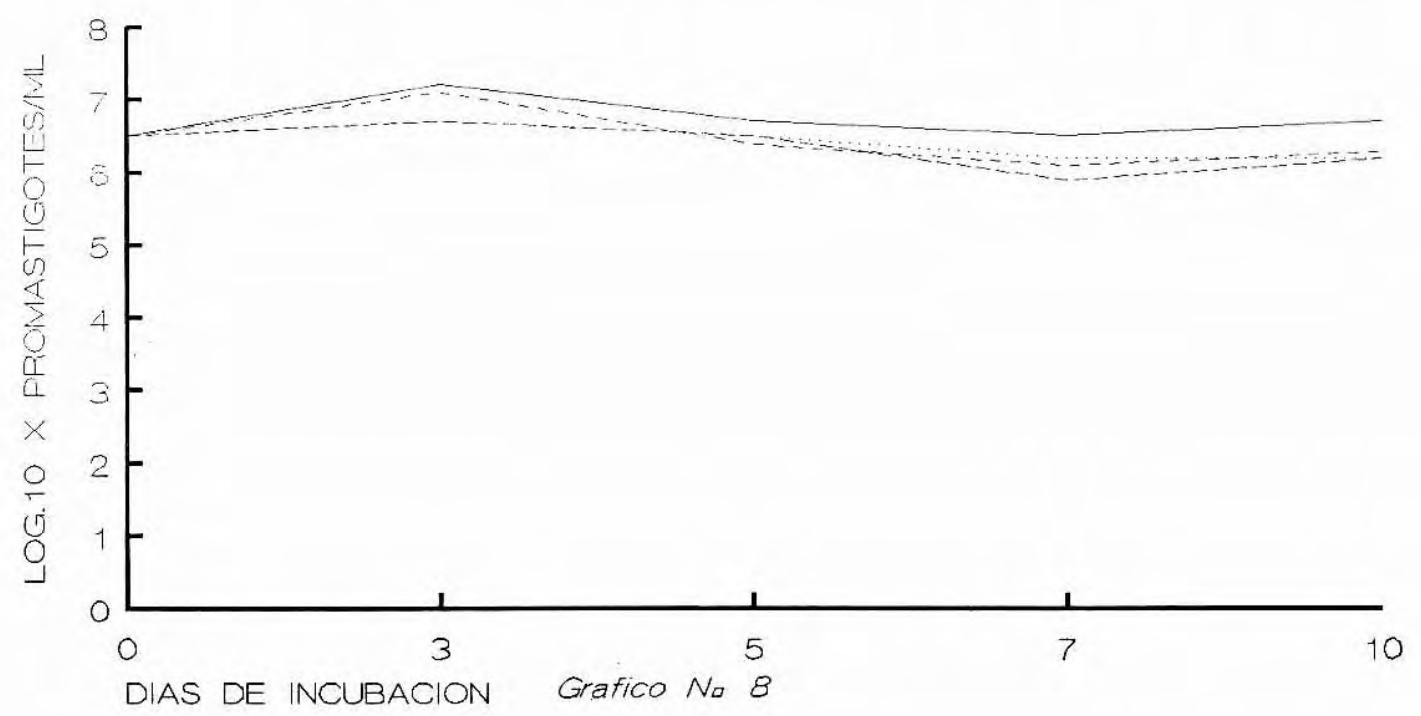

\section{LEISHMANIA MEXICANA AMAZONENSIS KANAMICINA}

- $0 \mathrm{ugr} / \mathrm{ml} \ldots-\ldots 50 \mathrm{ugr} / \mathrm{ml} \ldots-\ldots 100 \mathrm{ugr} / \mathrm{ml} \ldots \ldots . .200 \mathrm{ugr} / \mathrm{ml}$

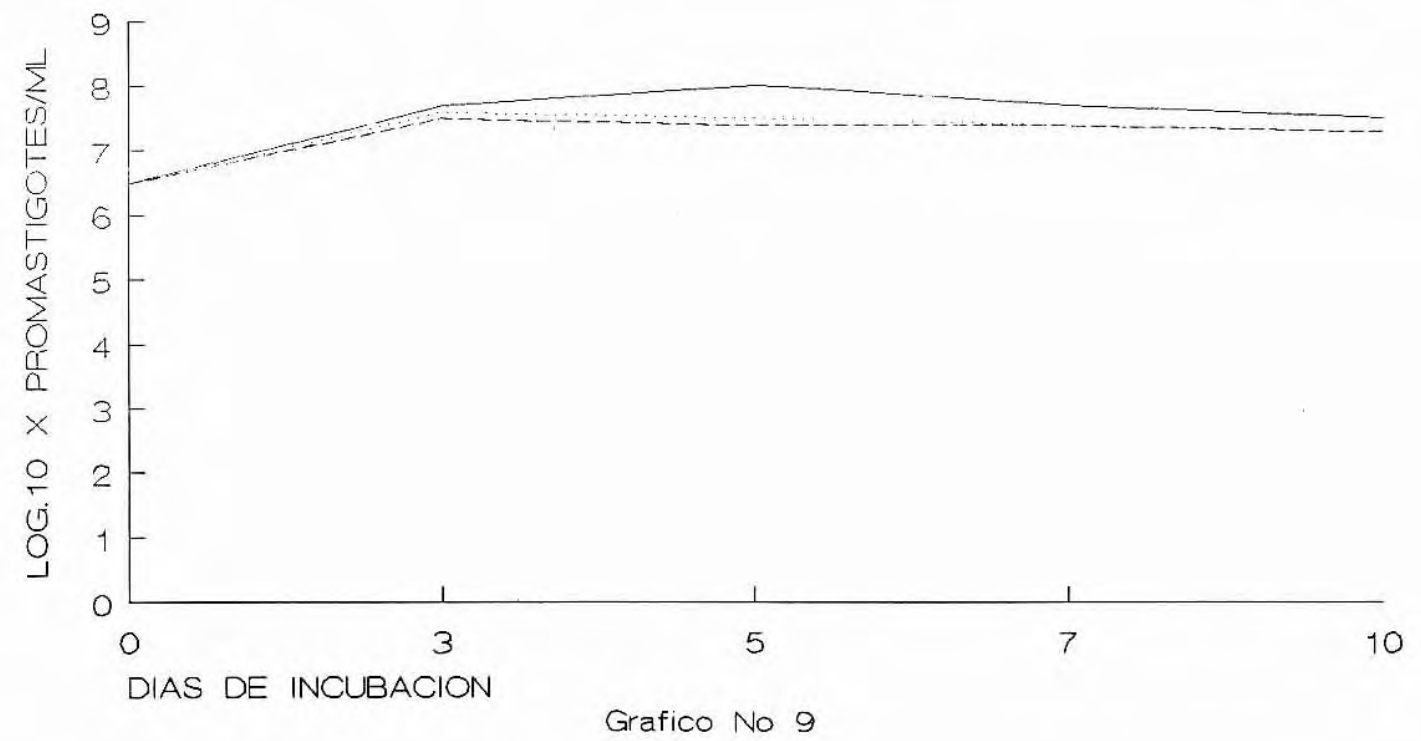


EVALUACION DEL EFECTO DEL ACIDO NALIDIXICO, AMPICILINA, KANAMICINA, PENICILINA G Y POLIXINA B,.....
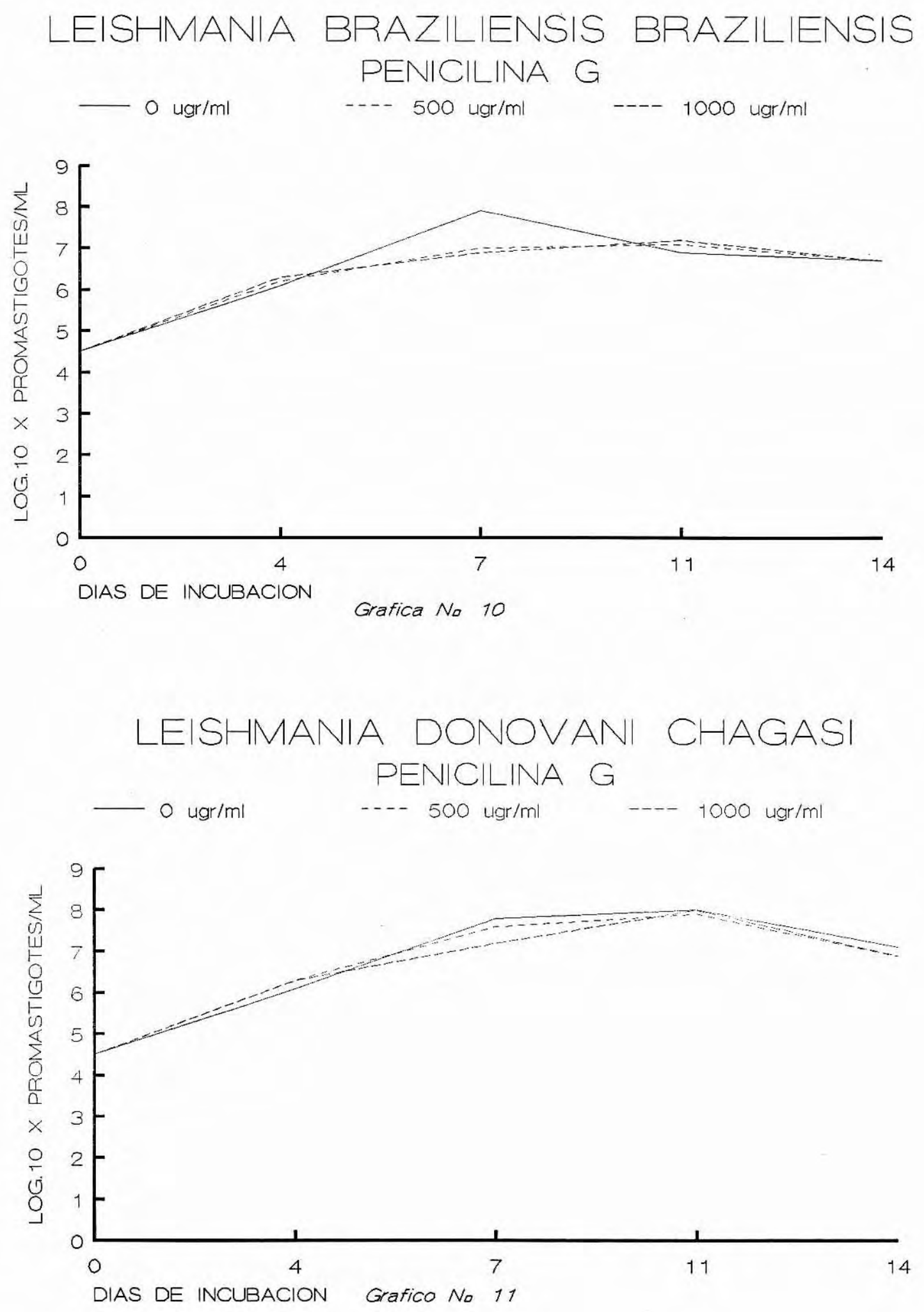


\section{LEISHMANIA MEXICANA AMAZONENSIS PENICILINA G \\ - $0 \mathrm{ugr} / \mathrm{ml} \quad \ldots 500 \mathrm{ugr} / \mathrm{ml} \quad \ldots-1000 \mathrm{ugr} / \mathrm{ml}$}

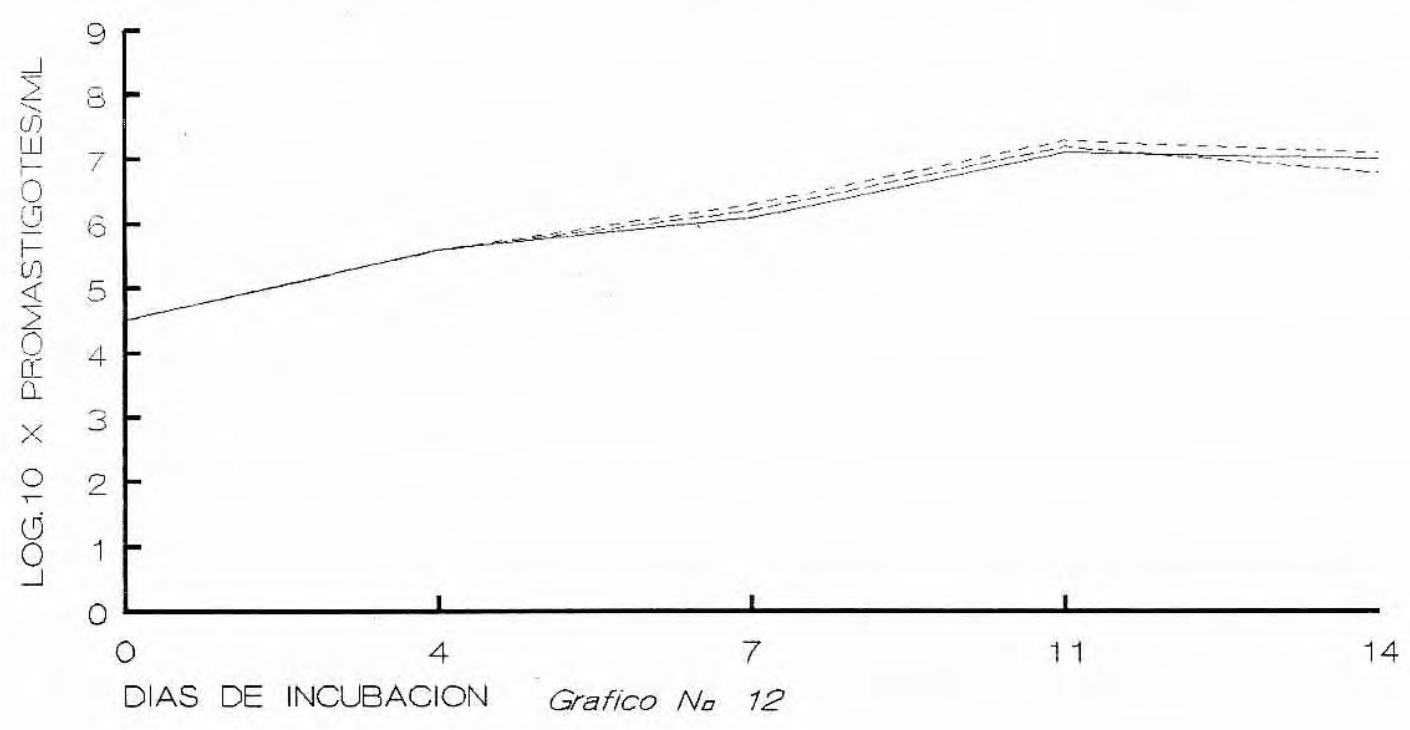

LEISHMANIA BRAZILIENSIS BRAZILIENSIS POLIMIXINA

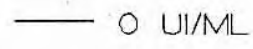

-..- $300 \mathrm{LI} / \mathrm{ML}$ $500 \cup / / M L$

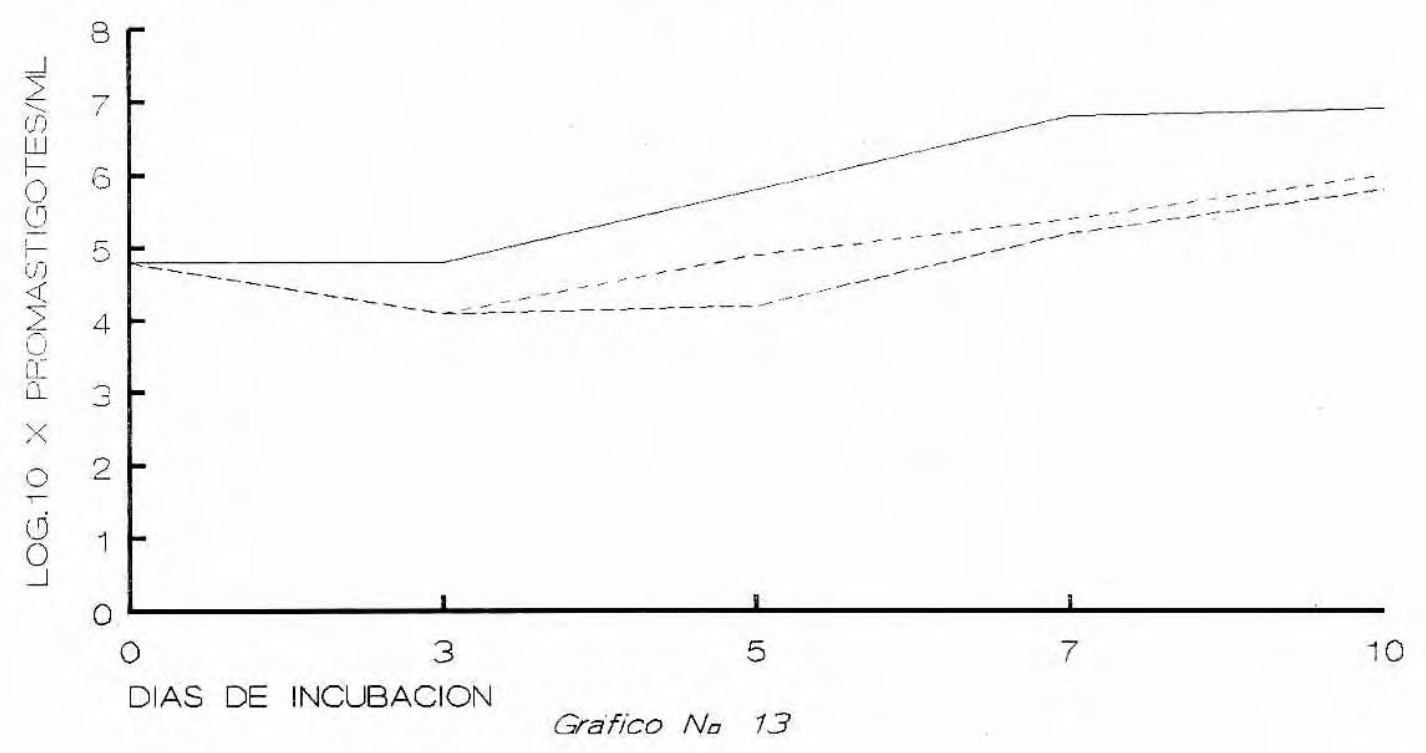


EVALUACION DEL EFECTO DEL ACIDO NALIDIXICO, AMPICILINA, KANAMICINA, PENICILINA G Y POLIXINA B, . ..
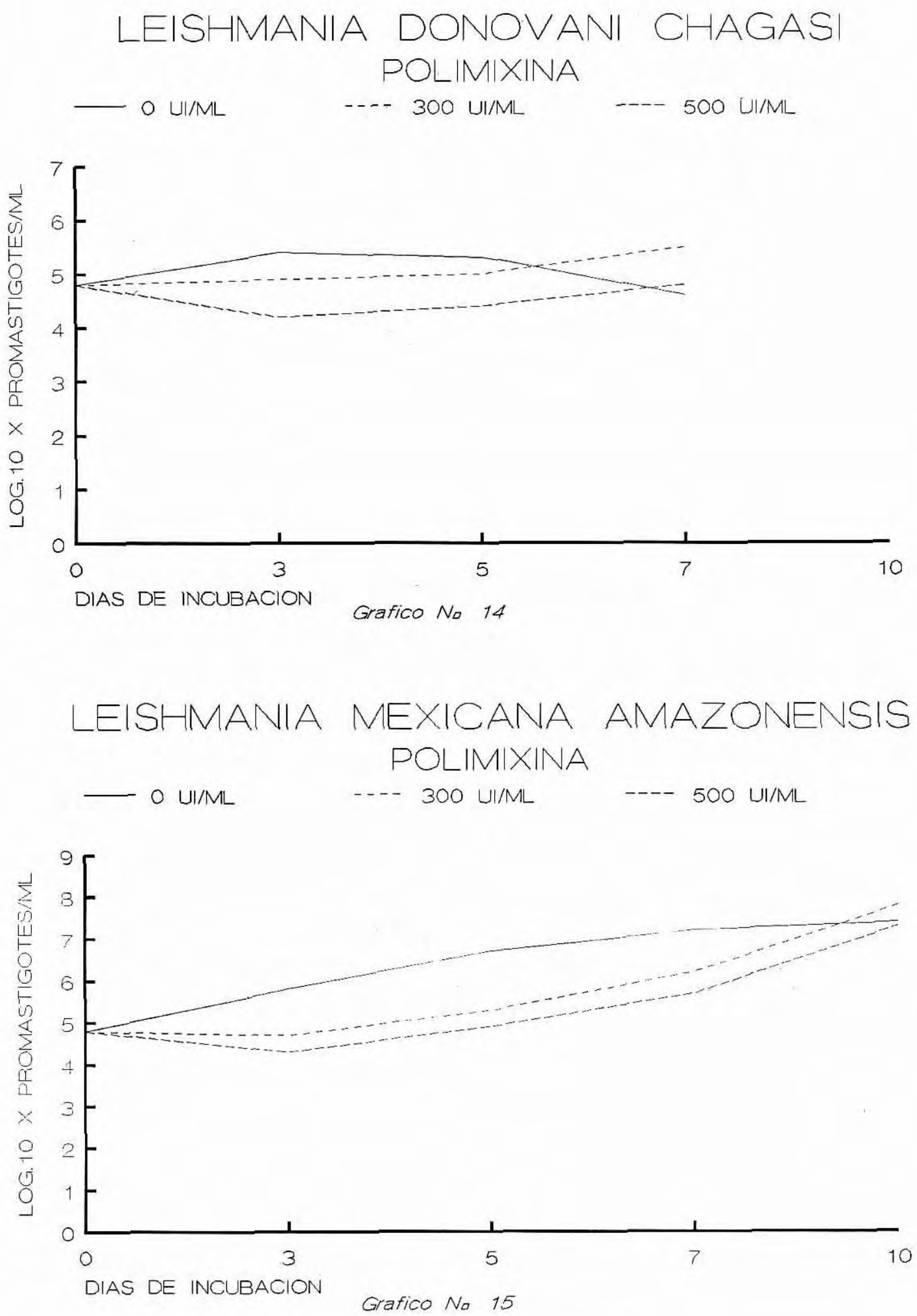


\section{DISCUSION}

El incremento poblacional de promastigotes de Leishmania en cultivo, en contacto con antimicrobianos y en distintas concentraciones del mismo, varía según el tipo de antimicrobiano utilizado y la cepa de Leishmania cultivada.

El ácido nalidíxico en concentraciones de 20 - $50 \mathrm{ug} / \mathrm{ml}$ impide el crecimiento de muchos bacilos Gram-negativos (7) y no sería conveniente emplearlo en cultivo de $L$. b. braziliensis debido a que disminuye notoriamente el número de promastigotes de la especie. Sin embargo, podría utilizarse en cultivos de $L$. d. chagasi y L.m.amazonensis en un rango de concentracion de $30-100 \mathrm{ug} / \mathrm{ml}$ y $30-50 \mathrm{ug} / \mathrm{ml}$ respectivamente favoreciendo así la no contaminación de los cultivos de estas cepas o la posible eliminación de bacilos Gram-negativos de las mismas.

En la concentración de $100 \mathrm{ug} / \mathrm{ml}$ la fase logarítmica de la cepa $L$. $m$.amazonensis se observó ligeramente inhibida hasta el día séptimo y a partir del cual recuperó su crecimiento comportándose similarmente al control. Este incremento poblacional podría deberse a la pérdida de actividad del bactericida y al crecimiento exhuberante que $L . \quad m$. amazonensis siempre presenta en cultivo.

La ampicilina es efectiva contra cocos y bacilos Gram-negativos en concentraciones de $3-6 \mathrm{ug} / \mathrm{ml}$ y $0.02-1.6 \mathrm{ug} / \mathrm{ml}$ respectivamente (7) y no presenta efecto desfavorable en el aumento de la población de promastigotes utilizando concentraciones tan altas como 100, 200 y $300 \mathrm{ug} / \mathrm{ml}$ en ninguna de las tres especies de Leishmania estudiadas, lo cual permite su uso con confiabilidad en cultivos.

La disminución en la población de promastigotes en $L . b$. braziliensis en presencia de ampicilina $100 \mathrm{ug} / \mathrm{ml}$ pudo deberse no a la concentración del antimicrobiano en sí, sino a la contaminación accidental con hongos que se presentó en el cultivo. Caso semejante ocurrió en el cultivo control de la cepa de $L$. $d$. chagasi a partir del día quinto.

La kanamicina es muy activa en concentraciones de $0.4-4.0 \mathrm{ug} / \mathrm{ml}$ contra estafilococos (7). Sigma ha utilizado este antibiótico contra bacterias Gram-positivas en cultivo celular sugiriendo concentraciones de trabajo de $10 \mathrm{ml} /$ Ly $2 \mathrm{ml} / \mathrm{L}$ si se emplea la kanamicina de $10 \mathrm{mg} /$ $\mathrm{ml}$ solución y $50 \mathrm{mg} / \mathrm{ml}$ solución respectivamente. La kanamicina podría ser empleada en concentraciones de $50-200 \mathrm{ug} / \mathrm{ml}$ en cultivo de $L$. b. braziliensis, L. d. chagasi y L. $m$. amazonensis sin que se altere la población de éstas y además se favorece el cultivo de una contaminación por estafilococos o bacterias Gram-positivas. La disminución en el crecimiento de parásitos se produce a partir del día tercero y los promastigotes aún se encuentran en fase logarítmica de crecimiento lo cual es una ventaja. Se recomienda el uso de kanamicina en cualquiera de las concentraciones usadas en las tres cepas de Leishmania experimentada. Sin embargo, sería preferible utilizar las concentraciones menores del antimicrobiano.

La penicilina $\mathrm{G}$ es muy efectiva contra todos los bacilos Gram-positivos y muchos bacilos Gram-negativos (7). Esta ha sido adicionada en cultivo de Leishmania en concentraciones de 50 $-300 \mathrm{UI} / \mathrm{ml}(8,9,10,11)$ y de $10.000 \mathrm{UI} / 5 \mathrm{ml}$ (12) para eliminar gérmenes. En nuestro estudio el emplear penicilina $G$ hasta concentraciones de $1000 \mathrm{ug} / \mathrm{ml}$ permitió conocer que éste por su gran espectro antimicrobiano puede ser utilizado en cualquier cultivo de Leishmania sin alterar el crecimiento de los parásitos.

La polimixina $B$ es utilizada algunas veces contra bacilos Gram-negativos (7). El número de flagelados en todas las cepas de Leishmania presentó una reducción muy notoria hasta el día tercero de incubación del cultivo y luego un incremento progresivo de parásitos. Tal comportamiento nos permite inferir que la polimixina $B$ ejerce un efecto adverso en el aumento del número de promastigotes in vitro en los primeros días del cultivo y el cual no puede continuar quizás a una posible inactivación rápida del antimicrobiano.

Algunas veces puede observarse resistencia de los microorganismos contaminantes a los antimicrobianos utilizados durante los cultivos de Leishmania. Ello podría obviarse analizando el tipo de contaminante tan pronto se detecte la contaminación y utilizando el antimicrobiano apropiado. Además se sugiere comenzar la descontaminación con las concentraciones bajas de los bactericidas evaluados e 
ir aumentando la concentración de éstos poco a poco hasta obtener una completa eliminación de los microorganismos. En aquellos casos donde se observe nuevamente resistencia se recomienda emplear cualquiera de los otros antibióticos evaluados en el presente trabajo como alternativas.

\section{SUMMARY}

The effect of several antibiotics (nalidixic acid, ampicillin, kanamycin, penicillin $\mathrm{G}$ and polimyxin B) concentrations was evaluated on promastigote growth of Leishmania braziliensis braziliensis, Leishmania donovani chagasi, and Leishmania mexicana amazonensis which had been maintenance in vitro. Penicillin $G$ and ampicillin could be added until concentrations of $1000 \mathrm{ug} / \mathrm{ml}$ and $500 \mathrm{ug} / \mathrm{ml}$, respectively, without any parasite alteration. Promastigote populations of all strains decreased after the addition of polimyxin B; consequently, this antibiotic is not recommended or useful in Leishmania cultures. Nalidixic acid and kanamycin may be added to Leishmania cultures, considering the particular Leishmania strain and the antimicrobial concentration chosen for it.

\section{AGRADECIMIENTOS}

Los autores agradecemos al Doctor Luis Carlos Orozco V., Jefe del Grupo de Micobacterias, por sus sugerencias en los aspectos bacteriológicos y estađísticos. Este trabajo se realizó con los auspicios del Instituto Nacional de Salud de Colombia y del Grant AI-2018 del National Institute of Health de Estados Unidos de América.

\section{BIBLIOGRAFIA}

1. Evans DA. Kinetoplastida. In: Taylor AER \& Baker JR,eds. Methods of cultivating parasites In vitro. London: Academic Press Inc., 1978: 55-78.

2. Evans DA. Leishmania. In: In vitro methods for parasite cultivation. London: Academic Press Inc., 1987: 1-36.

3. Lamy L, Wonde T, Lamy $\mathbf{H}$. Activite de l'amphotericine B sur Leishmania donovani dans les macrophages de souris entretenus in vitro. Bull Soc Pathol Exotiq 1966; 59: 964-8.

4. Jiménez G De, Ercoli N. Effect of drugs on various Leishmania isolates and succinic dehydrogenase inhibition. Exp Parasitol 1965; 17: 302-8.

5. Neal RA, Croft SL. An in vitro system for determining the activity of compounds against the intracellular amastigote form of Leishmaria donovani. J Antimicrob Chemother 1984; 463-75.

6. Duque S, Cáceres E, Corredor A. Comportamiento de flagelados de la Familia Trypanosomatidae en dos medios de cultivo modificados. Biomédica 1988; 8: 21-7.

7. Braude AI. Antimicrobial drug therapy. Vol VIII.Philadelphia: WB Saunders, 1976: 1-218

8. Ray R, Ghose AC. Cultivation of Leishmania donovani in vitro in a high yielding liquid culture medium. Indian $\mathrm{J}$ Med Res 1980; 71: 203-6.

9. Chaudhuri G, Chatterjee TK, Banerjeee AB. Growth factor requirements for in vitro growth of Leishmania donovani.Indian J Med Res 1982; 76: 157-63.

10. Hockmeyer WT, Kager PA, Rees PH Hendricks LD. The culture of Leishmania donovani in Schneider's insect medium: its value in the diagnosis and management of patients with visceral leishmaniasis. Trans R Soc Trop Med Hyg 1981; 75: 861-63.

11. Rassam MB, Al-Mudhaffar SA. The primary isolation of Leishmania donovani from Iraq on different culture media. Ann Trop Med Parasitol 1979; 73: 345-47.

12. Neal RA. Leishmania major: culture media, mouse strains, and promastigote virulence and infectivity. Exp Parasitol 1984; 57:269-73. 